\title{
Commentary: Viewing photos and reading nouns of natural graspable objects similarly modulate motor responses
}

\author{
Stergios Makris * \\ Department of Psychology, Edge Hill University, Ormskirk, UK
}

Keywords: objects, nouns, affordance, motor cortex, visual perception

\section{A commentary on}

Viewing photos and reading nouns of natural graspable objects similarly modulate motor responses

by Marino, B. F. M., Sirianni, M., Volta, R. D., Magliocco, F., Silipo, F., Quattrone, A., et al. (2014). Front. Hum. Neurosci. 8:968. doi: 10.3389/fnhum.2014.00968

\section{OPEN ACCESS}

Edited by:

Arthur M. Jacobs,

Freie Universität Berlin, Germany

Reviewed by:

Anna M. Borghi,

University of Bologna and Institute of Cognitive Sciences and Technologies,

Italy

*Correspondence:

Stergios Makris,

makriss@edgehill.ac.uk

Received: 05 February 2015 Accepted: 27 May 2015

Published: 09 June 2015

Citation:

Makris S (2015) Commentary: Viewing photos and reading nouns of natural graspable objects similarly modulate motor responses.

Front. Hum. Neurosci. 9:337. doi: 10.3389/fnhum.2015.00337
Marino et al. (2014) in their paper (Frontiers in Human Neuroscience) have tried to investigate how the semantic processing of graspable objects involves an activation of the motor cortex in line with the affordance hypothesis originally proposed by Gibson (1979). They devised a go/non-go behavioral task, during which they presented photos or nouns of natural graspable and nongraspable objects, while for some of the trials the stimuli viewed were scrambled images of the same objects or pseudowords. Participants viewed the stimuli for a period of $150 \mathrm{~ms}$, after which they had to respond to a go or non-go signal (whether the stimuli were real or not) as part of a semantic task. They found that subjects' responses were slower when they were viewing the photos or reading the nouns of graspable objects, as compared to non-graspable ones. The authors explained that this delay in motor responses following the images or nouns of graspable objects is a proof of the motor cortex involvement in the semantic processing of objects that afford a motoric action. Even though these findings are in line with some previous reports about an early activation and involvement of the motor system in language and semantic processes (Pulvermueller et al., 2001, 2005), in this commentary we argue that the stimulus onset asynchrony (SOA) of $150 \mathrm{~ms}$ is too early for an affordance effect to occur and thus, we will try to provide a different account of their results and leave some room for further insight on the topic.

There is mounting research evidence suggesting that the simple viewing of objects with action significance can stimulate the motor cortex into generating appropriate motor plans, even in cases that there is no action intention (Tucker and Ellis, 1998; Ellis and Tucker, 2000; Makris et al., 2011, 2013). This is the theory of affordances as originally described by Gibson (1979). Within the affordance literature a key aspect for investigation has been the temporal evolution of the affordance effect. Ellis and Tucker (2000) in a series of behavioral investigations have suggested that the affordance effect is slow and gradually develops $500 \mathrm{~ms}$ after the stimulus onset. On the other hand, in previous research with TMS we have proved by means of measures of corticospinal excitability (motor evoked potentials) that the affordance effect is present at $300 \mathrm{~ms}$ and rapidly dissipates $500 \mathrm{~ms}$ after the stimulus onset (Makris et al., 2011, 2013). Most importantly, in the aforementioned studies we investigated the generation of affordances $150 \mathrm{~ms}$ after the subjects were presented with graspable objects, but 
we did not find any evidence of involvement of the motor cortex as a result of that. In that sense, the results of Marino et al. (2014) are in contrast with previously reported findings.

Furthermore, Cisek (2006, 2007) has provided a compelling explanation of this delay in the formation of the affordance effect, known as the "affordance competition hypothesis." According to this, in response to attended objects with action significance, multiple competing motor plans are generated across different regions of the motor cortex and through mutual inhibitory connections, a single motor winning act prevails. With this in mind, it is possible that graspable objects suddenly appearing on screen can automatically grab exogenous attention (Yantis and Jonides, 1984) and then for a rapid period after stimulus onset ( $\sim 100-150 \mathrm{~ms})$ attention is subsequently withdrawn from the objects in display, leading to a rebalance of the affordance-driven motor plans (see also Makris et al., 2011). This is particularly interesting, as it could provide an alternative explanation for the observed difference in response latencies between graspable and non-graspable objects in the Marino et al. (2014) study. Indeed, it could be that $150 \mathrm{~ms}$ after the presentation of the stimuli, exogenous-like attention was withdrawn from the graspable only

\section{References}

Cisek, P. (2006). Integrated neural processes for defining potential actions and deciding between them: a computational model. J. Neurosci. 26, 9761-9770. doi: 10.1523/JNEUROSCI.5605-05.2006

Cisek, P. (2007). Cortical mechanisms of action selection: the affordance competition hypothesis. Philosoph. Trans. R. Soc. B 362, 1585-1599. doi: 10.1098/rstb.2007.2054

Ellis, R., and Tucker, M. (2000). Micro-affordance: the potentiation of components of action by seen objects. Br. J. Psychol. 91, 451-471. doi: $10.1348 / 000712600161934$

Gibson, J. J. (1979). The Ecological Approach to Visual Perception. Boston, MA: Houghton Mifflin

Makris, S., Grant, S., Hadar, A. A., and Yarrow, K. (2013). Binocular vision enhances a rapidly evolving affordance priming effect: behavioural and TMS evidence. Brain Cogn. 83, 279-287. doi: 10.1016/j.bandc.2013.09.004

Makris, S., Hadar, A. A., and Yarrow, K. (2011). Viewing objects and planning actions: on the potentiation of grasping behaviours by visual objects. Brain Cogn. 77, 257-264. doi: 10.1016/j.bandc.2011.08.002

Marino, B. F. M., Sirianni, M., Volta, R. D., Magliocco, F., Silipo, F., Quattrone, A., et al. (2014). Viewing photos and reading nouns of natural graspable objects similarly modulate motor responses. Front. Hum. Neurosci. 8:968. doi: 10.3389/fnhum.2014.00968

Pulvermueller, F., Haerle, M., and Hummel, F. (2001). Walking or talking? Behavioral and neurophysiological correlates of action objects and not the non-graspable ones. This way, participants would have to re-direct their attention to the graspable objects in order to resolve the semantic task and thus, this process would have some cost in the timing of their responses. Hence, the reported results may not reflect the involvement of the motor system in the semantic processing of graspable stimuli per se, but instead an effect of purely attentional processes. Nevertheless, this is only an alternative proposition to the current findings by Marino et al. (2014) and even so we cannot entirely rule out a relationship between attentional and motor processes (i.e., premotor theory of attention, Rizzolatti et al., 1994).

Overall, it is apparent that the affordance effect remains a compelling topic within cognitive psychology and neuroscience, as it is the need to better understand the underlying visual, attention and motor processes. Theories of a direct or indirect route between visual perception, semantic processing and motor planning may appear contradicting, but in our opinion it could be that they are all providing a valuable insight in the better understanding of human cognition and perception. Hence, it is important for future research to validate or expand upon these insights. verb processing. Brain Lang. 78, 143-168. doi: 10.1006/brln. 2000.2390

Pulvermueller, F., Hauk, O., Nikulin, V. V., and Ilmoniemi, R. J. (2005). Functional links between motor and language systems. Eur. J. Neurosci. 21, 793-797. doi: 10.1111/j.1460-9568.2005.03900.x

Rizzolatti, G., Riggio, L., and Sheliga, B. (1994). "Space and selective attention," in. Attention and Performance XV, eds C. Umilta, M. Moscovitch (Cambridge, MA: MIT Press), 231-265.

Tucker, M., and Ellis, R. (1998). On the relations between seen objects and components of potential actions. J. Exp. Psychol. Hum. Percept. Perform. 24, 830- 846. doi: 10.1037/0096-1523.24.3.830

Yantis, S., and Jonides, J. (1984). Abrupt visual onsets and selective attention: evidence from visual search. J. Exp. Psychol. Hum. Percept. Perform. 10, 601-621. doi: 10.1037/0096-1523.10.5.601

Conflict of Interest Statement: The author declares that the research was conducted in the absence of any commercial or financial relationships that could be construed as a potential conflict of interest.

Copyright $\odot 2015$ Makris. This is an open-access article distributed under the terms of the Creative Commons Attribution License (CC BY). The use, distribution or reproduction in other forums is permitted, provided the original author(s) or licensor are credited and that the original publication in this journal is cited, in accordance with accepted academic practice. No use, distribution or reproduction is permitted which does not comply with these terms. 